\title{
Integrating Finite Element Method with GAs to Estimate the Scour Depth of Bridge
}

\author{
Chung-Wei Feng, Hsun-Yi Huang, and Shen-Haw Ju
}

\begin{abstract}
Bridge scour is one of the major reasons to cause bridge failure and bring serious disaster. As a preventive against disaster the scour depth around a bridge pier is an important index to evaluate the condition of the bridge. However, to detect the scour depth around bridge piers is hard task since the bridge foundation is under water. In this study, an approach which combines finite element method and genetic algorithms is used to estimate the bridge scour depth via the variation in the natural frequency of the bridge structure and conduct a genetic formula for scour bridge. In this paper, soil strength and pile length compare with natural frequency within different bridge scour depth is discussed. And to exam the approach, two types of bridge pile arrangement are used.
\end{abstract}

Index Terms-Bridge scour, finite element method, genetic algorithms, natural frequency

\section{INTRODUCTION}

To ensure the bridge safety is an important task to the government. Not only because bridges are the crucial components of traffic system but also the failure may cause people death and property loss. The most common reasons for bridge failures include structural and design deficiencies, corrosion, construction and supervision mistakes, accidental overload and impact, lack of maintenance and inspection, and scour. However, in the previous studies, scour is considered as one of the major reason for bridge failure. Shirole and Holt who observed over 1,000 failed bridges in United State between 1960 to 1990 recognize that $60 \%$ of these failures are due to scour [1]. Wardhana and Hadipriono categorize over 500 failure bridges in the United State from 1989 to 2000 as well as Biezma and Schanack also concluded the scour is one of the major reasons for bridge failures [2], [3]. In addition, bridge failure due to scour tends to occur suddenly and without prior warning. Constantly, having awareness to the bridge scour condition is important.

Considering the scour as the critical cause of bridge failure, numerous studies pay effort to discussing the interaction between bridge foundation and hydrologic environment [4]-[6]. Most of them used small-scale laboratory experiment with the consideration of various factors such as the depth of water, average velocity of flow, and diameter of sand in order to find out the scour mechanism. But due to environmental factors, to conclude the mechanics of bridge scour in various conditions are still hard and need more investigation. On the

Manuscript received February 8, 2013; revised May 7, 2013. This material is based on work supported by the National Science Council, Taiwan under Award NSC 101-2218-E-002-002-.

The authors are with Department of Civil Engineering in National Cheng Kung University, Tainan, Taiwan (e-mail: cfeng@mail.ncku.edu.tw, n6896115@mail.ncku.edu.tw,juju@mail.ncku.edu.tw). other hand, to know the depth of pile exposure is intuitional to evaluate the state of bridge. However, the pile exposure cannot be always observed directly, since piles are often under water. And the detection devices installed under water are often unstable, especially at the condition of flood. Therefore, there are also many researches that focus on the development of scour depth prediction method. Yanmaz and Altinbilek performed a time-dependent estimation of the maximum possible scour depth around bridge piers [7]. Firat and Gungor used artificial neural network methods to predict the equilibrium scour depth [8]. Kaya, Najafzadeh and Barani used different artificial intelligence approaches to predict the maximum scour depth [9], [10]. However most of models require predefined conditions and can only be applied to certain environment. As a result, existing methods do not always produce reasonable results for scour predictions [11].

In this study, an integrated model that combines Genetic Algorithms (GAs) and finite element simulation technology is developed to estimate the scour depth around bridge piers and conduct a genetic formula by using the natural frequency. Since natural frequency varies with the scour depth, it is a suitable proxy to detect the scour depth around bridge piers. A series of simulations are first performed on a testing bridge to determine the possible values of the natural frequencies by setting different scour depths and environmental conditions such as soil distribution, foundation dimensions, and etc. Since simulations generate a huge amount of data, GAs is applied to find the relationship among the scour depth, natural frequency, and all the other environmental variables. Thus, the manager can notice and evaluate the bridge safety immediately especially in flood.

\section{Methodology}

\section{A. Simulation of Bridge Natural Frequency}

Structure natural frequency calculation is a motion of a dynamic problem. For the problem the equation is:

$$
\mathbf{M} \ddot{\mathbf{X}}+\mathbf{C} \dot{\mathbf{X}}+\mathbf{K X}=\mathbf{F}
$$

where $\mathrm{M}, \mathrm{C}$, and $\mathrm{K}$ are mass, damping, and stiffness matrices, respectively, $\mathrm{X}$ is the displacement vector, and $\mathrm{F}$ is the external force vector. If the damping and external force are neglected, one obtains:

$$
\mathbf{M X}+\mathbf{K X}=\mathbf{0}
$$

The displacement vector is assumed to be $\mathrm{X}=\Phi \mathrm{e}^{\mathrm{i} \omega}$, and equation (2) changes to

$$
\left(K-\omega^{2} M\right) \Phi=0
$$


Equation (3) is a standard eigenproblem, where $\omega$ is a natural frequency and $\Phi$ is a modal shape.

To simulate the eigenproblem of bridges accurately, the foundation and soil cannot be ignored, since the bridge foundation often contains a large portion of the total structure. In particular, the natural frequency of a scour bridge should be sensitive to the exposure of the bridge foundation. Therefore, finite element method as a suitable tool is used. Fig. 1 and 2 show the finite element mesh of the bridge with and without the exposure of the foundation. The bridge consists of multi-span simply supported beams for the Taiwan high-speed rail in Tainan, Taiwan (Fig. 3).

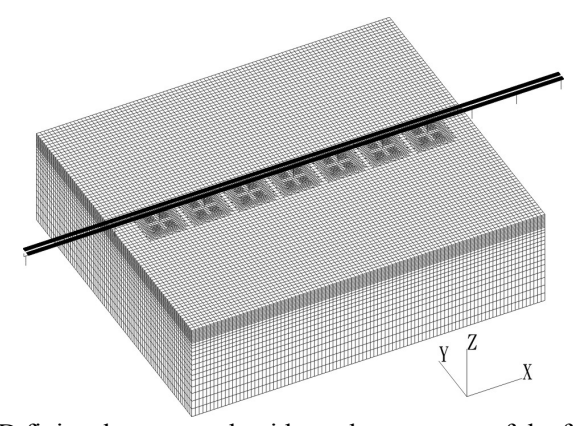

Fig. 1. 3D finite element mesh without the exposure of the foundation

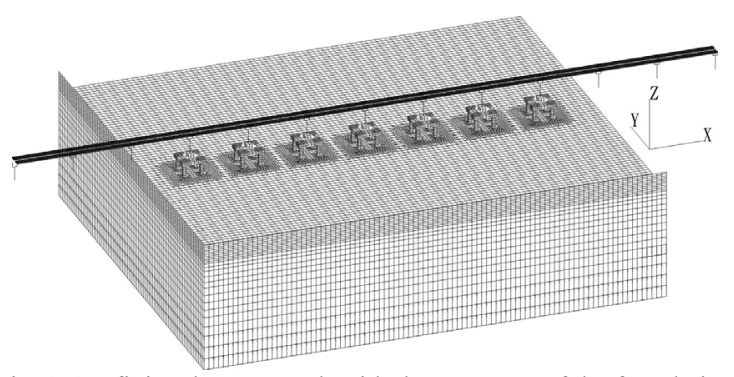

Fig. 2. 3D finite element mesh with the exposure of the foundation

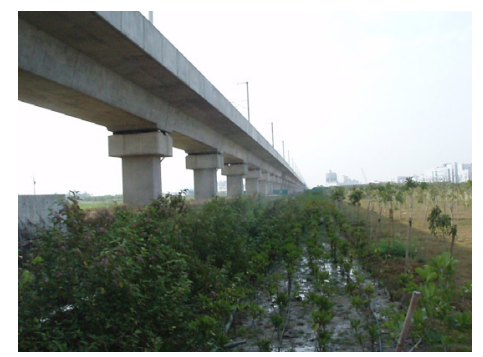

Fig. 3. Taiwan high-speed railway in Tainan, Taiwan

The total number of natural frequencies and modal shapes is the same as the total number of degrees of freedom (NDF) of the finite element mesh. Therefore, that comes out with two problems: (a) how to solve the large-scale eigenproblem and (b) determining which solution is the major standing frequency for the natural frequency of the bridge. For first issue, the subspace iteration method was used to solve the eigenproblem of (2). The major advantage of this method is that first $\mathrm{N}$ eigenvalues and eigenvectors can be obtained, where $\mathrm{N}$ can be decided by users. For a finite element problem with large degrees of freedom such as a million or greater, the subspace iteration method is efficient, because it often requires only the first few modes such as 40 to 60 modes. For second issue, the effective mass above the soil surface is used to determine the natural frequencies of the bridge structure. Therefore, the effective mass ratio can be used to represent the importance of each mode under the seismic load and determines the major natural frequency of the bridge. If the ratio is large, such as $30 \%$, this mode can be categorized as a mode shape in that direction. Fig. 4 shows the simulation result after the finite element calculation. The natural frequencies are verified by field experiment. Errors in the $\mathrm{x}$ direction and $\mathrm{y}$ direction are about $2.64 \% \sim 4.58 \%$ and $1.42 \% \sim 4.99 \%$. The finite element results are in acceptable accuracy. Note that the $\mathrm{X}$-axis is defined along the bridge direction, and the $\mathrm{Y}$-axis is perpendicular to the bridge (referring to the transverse direction). The natural frequency used in this study is in the $Y$ direction because it is more sensitive. More details of the technique and information can refer to [12], [13].

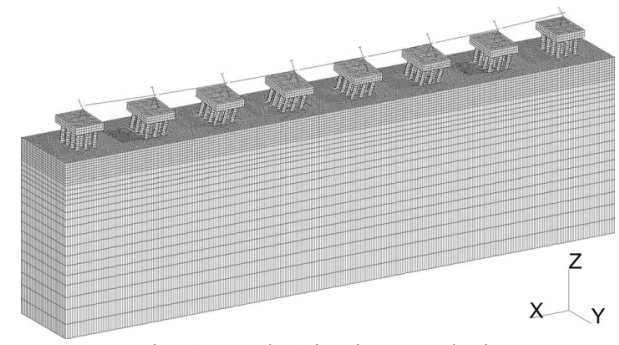

Fig. 4. Mode 1 in eigen-analysis

\section{B. Genetic Algorithms for Fitting Formula}

After a series of finite element simulation corresponding to various parameters setting, a huge numbers of data will be generated and which make it difficult to conduct a universal formulation to predict the scour depth. Genetic algorithms (GAs) are then applied to find an approximate relationship among the bridge natural frequency, scour depth and various environmental variables (ex. pile length, soil strength and etc.).

GAs are search algorithms developed by Holland [14] which are based on the mechanics of natural selection and genetics to search through decision space for optimal solutions [15]. Fig. 5 shows a brief GA process. In GAs, a string (chromosome combination) represents a potential solution to a problem. Each string is evaluated on its performance with respect to the fitness function (objective function). The crossover and mutation schemes will exchange the information (gene) between strings to produce various solutions. The string with higher performance will be selected with higher probability in selection scheme and more possibly to be the final answer.

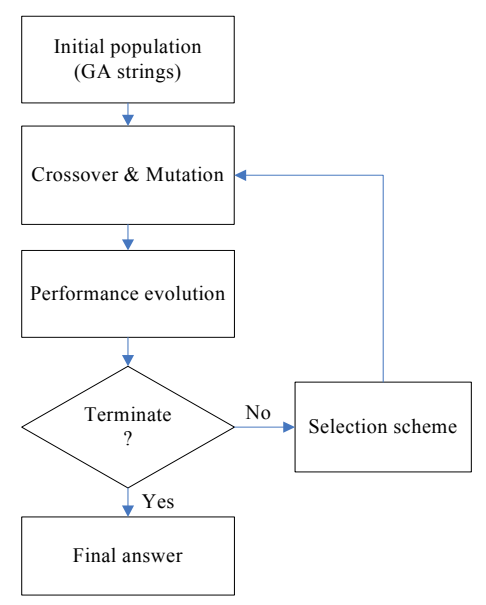

Fig. 5. Flowchart of GA 
In this problem, the general form of equation can be written as:

$$
Y=f(X, \theta)+\varepsilon
$$

where $Y$ is the dependent variable, $X$ is an $(n \times 1)$ vector of independent variables, $\theta$ is a $(k \times 1)$ parameter vector, and $\varepsilon$ is a random error.

$f(X, \theta)$ could be displayed in various forms such as $(5)$ to make the fitting function more suitable.

$$
Y_{i}=\theta_{0} \operatorname{Sin}\left(X_{i}^{\theta_{1}}\right)+\varepsilon_{i}
$$

As a result, a GA string which represents a potential solution for fitting formula should determine the variables including $\theta$, numerical parameters to adjust the dependent variable, and the transform functions such as trigonometric function.

The numerical parameter $(\theta)$ can be displayed as:

$$
\theta=\alpha \times 10^{\beta}
$$

Set $\alpha$ is a number around -1 to 1 with acceptable precise such as 6 decimal places. And also set $\beta$ within an acceptable range, such as 0 to 3 and accurate to 3 decimal places. As a result, $\alpha$ and $\beta$ could be coded in binary. Then, the GA strings of $\theta$ are defined.

For the selection of transform functions, a $100 \%$ percentage number is divided into equal parts to represent each transform functions. Then a random number between 0 and 1 is used to determine the selection of transform function by means of the location of the percentage. The random number is then coded in binary as the GA strings for transform functions selection. Fig. 6 illustrates an example with 2 transform functions.

Four arithmetic operations between each variable are also coded in binary with 2 bits (string length).

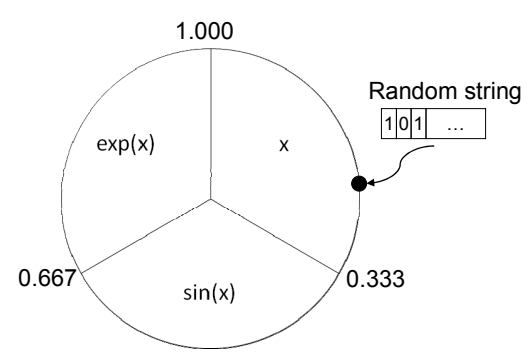

Fig. 6. Illustration of transform function selection

In this study, mean error is finally used to measure the performance of the GA string (solution). The error means the different between the result of fitting formula and the scour depth which is simulated by finite element analysis. When the error is lower than an acceptable level, GA process finish and the formula is conducted.

\section{CAse Study}

The case bridge is a 7-span pre-stressed box girder bridge with a span length of $30 \mathrm{~m}$, in which simply supported girders are used. The bridge section is shown in Fig. 7. The length of the bridge pier foundation is $5 \mathrm{~m}$, and the dimensions are 3.5 $\mathrm{m} \times 3.5 \mathrm{~m}$. The diameter of each pile is $1.5 \mathrm{~m}$. The Young's modulus of the bridge piers, caps, and piles is $2.4 \times 10^{7}$ $\mathrm{kN} / \mathrm{m}^{2}$. A value of $2.94 \times 10^{7} \mathrm{kN} / \mathrm{m}^{2}$ is used for the bridge beams. The total mass density and Poisson ratio of the entire bridge structure are $2.4 \mathrm{~T} / \mathrm{m}^{3}$ and 0.25 , respectively. The dimensions of the soil layer are set to be $240 \mathrm{~m}$ in the $\mathrm{X}$ direction and $33.75 \mathrm{~m}$ in the $\mathrm{Y}$ direction.

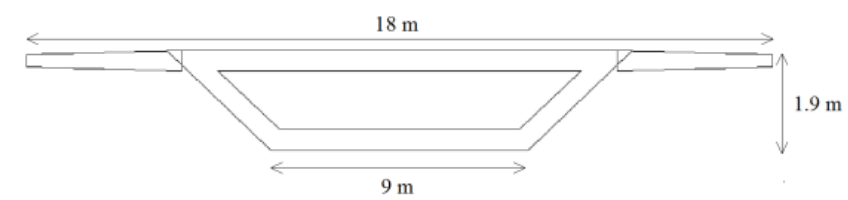

Fig. 7. Size of bridge section.

To exam the presented approach, the pile length is considered as a variable, with 31,49 , and $61 \mathrm{~m}$ taken as the three possible settings in this study. The soil property as another variable is simplified and presented as a uniform soil strength, which is the Young's modulus of the soil. In this study, six soil strengths are considered: $0.1,0.2,0.3,0.4,0.5$ and $2 \mathrm{BNt} / \mathrm{m}^{2}$. Finally, nine scour depths - 0, 1, 2, 4, 6, 8, 11, 14 , and $17 \mathrm{~m}$ are simulated to calculate the bridge natural frequencies for each combinatorial scenario. In addition, two types of pile arrangement shown in Fig. 8 are used to check the effectiveness of the approach in this study.

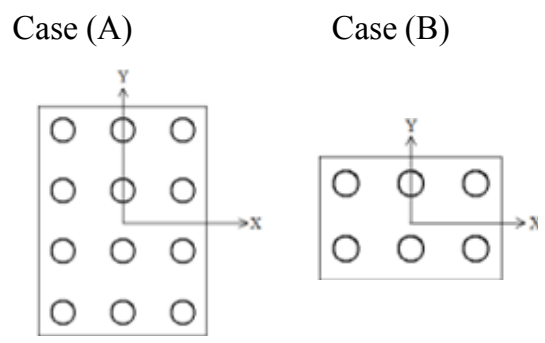

Fig. 8. Two pile arrangements

For GAs setting, five transform functions are set. They are: do nothing, sine, cosine, natural $\log (\ln )$, and Exponential function (EXP). Table I shows the results for two cases. The mean errors in case (A) and (B) are $1.1801 \mathrm{~m}$ and $0.5274 \mathrm{~m}$. Both cases have acceptable performance. The approach is valid.

TABLE I: RESULTS FOR TwO CASES

\begin{tabular}{ccc}
\hline Case & Fitting formula & Error $(\mathrm{m})$ \\
\hline (A) & $\mathrm{y}=-0.9045393 \times \operatorname{EXP}\left(\mathrm{x}_{1}{ }^{1.639565}\right)+12.62631 \times \cos \left(\mathrm{x}_{2}{ }^{-14.84153}\right)$ & 1.1801 \\
& $\div(-13.97268) \mathrm{x}_{3}{ }^{-0.9412117}+23.15047$ & \\
(B) & $\mathrm{y}=-7.935675 \mathrm{x}_{1}{ }^{1.569677}-7.649812 \mathrm{x}_{2}{ }^{-8.810525}-1.742127 \mathrm{x}_{3}{ }^{-0.5739592}$ & 0.5274 \\
& +26.36863 & \\
\hline
\end{tabular}

Note: $\mathrm{y}=$ scour depth; $\mathrm{x}_{1}=$ bridge natural frequency; $\mathrm{x}_{2}=$ pile length; $\mathrm{x}_{3}=$ soil strength.

\section{CONCLUSIONS}

In this study an integrated model that combines finite element method and genetic algorithms to estimate the scour depth around bridge piers by using the natural frequency is introduced. Bridge scour depth is an important index to evaluate the bridge safety. However, piles are always under water especially in the flood and which make it difficult to 
measure the bridge scour depth using contact measurement schemes. The natural frequency of bridges is thus an alternative proxy to measure the scour depth since natural frequency varies with different scour depth.

To simulate the scour bridge and calculate the natural frequencies, finite element method is used. Through a series of computer simulation by setting different conditions, a large numbers of natural frequencies are generated. Genetic algorithms are then applied to find an approximate relationship among the bridge scour depth, natural frequency and all the other environmental variables and conduct a genetic formula. Thus, the scour depth of bridge could be easily computed in the field experiment by using natural frequency.

Finally, 3 pile length, 6 different soil strength, and 9 scour depths corresponding to 2 types of pile arrangement simple supported bridge are used to exam the approach. Two conducted formula with mean error are $1.1801 \mathrm{~m}$ and 0.5274 $\mathrm{m}$. The presented approach obtains acceptable performance.

\section{REFERENCES}

[1] A. M. Shirole and R. C. Holt, "Planning for a comprehensive bridge safety assurance program," Transp. Res. Rec.,pp. 137-142, 1991

[2] K. Wardhana and F. C. Hadipriono, "Analysis of recent bridge failures in the United States," Journal of Performance of Constructed Facilities, vol. 17 , pp. 144-150, 2003

[3] M. V. Biezma and F. Schanack, "Collapse of Steel Bridges," Journal of Performance of Constructed Facilities, vol. 21, pp. 398-405, 2007

[4] B. Dargahi, "Controlling mechanism of local scouring," Journal of Hydraulic Engineering, vol. 116, pp. 1197-1214, 1990

[5] B. W. Melville and A. J. Raudkivi, "Effects of Foundation Geometry on Bridge Pier Scour," Journal of Hydraulic Engineering, vol. 122, pp. 203-209, 1996

[6] B. W. Melville and S. E. Coleman, Bridge Scour, New Zealand: the University of Auckland, 2000.

[7] A. M. Yanmaz and H. D. Altinbilek, "Study of time-dependent local scour around bridge piers," Journal of Hydraulic Engineering, vol. 117 , pp. 1247-1268, 1991.

[8] M. Firat and M. Gungor, "Generalized regression neural networks and feed forward neural networks for prediction of scour depth around bridge piers," Advances in Engineering Software, vol. 40, pp. 731-737, 2009.

[9] A. Kaya, "Artificial neural network study of observed pattern of scour depth around bridge piers," Computers and Geotechnics, vol. 37, pp. 413-418, 2010.

[10] M. Najafzadeh and G.-A. Barani, "Comparison of group method of data handling based genetic programming and back propagation systems to predict scour depth around bridge piers," Scientia Iranica, vol. 18, pp. 1207-1213, 2011.

[11] Z.-K. Mohammad, A.-A. Beheshti, and A.-A. Behzad, "Estimation of current-induced scour depth around pile groups using neural network and adaptive neuro-fuzzy inference system," Applied Soft Computing, vol. 9, pp. 746-755, 2009

[12] C.-W. Feng, S.-H. Ju, H.-Y. Huang, and P.-S. Chang, "Using Genetic Algorithms to Estimate the Scour Depth around the Bridge Pier," in Proc. 28th International Symposium on Automation and Robotics in Construction, Seoul, Korea, 2011, pp. 514-519.

[13] S.-H. Ju and K. S. KUNG, "Mass types, element orders and solution schemes for the richards equation," Computers \& Geosciences, vol. 23, pp. 175-187, 1997.

[14] J. H. Holland, Adaptation in Natural and Artificial Systems, Ann Arbor, Mich: University of Michigan Press, 1975.

[15] D. E. Goldberg, Genetic Algorithms in Search, Addison-Wesley, 1989.

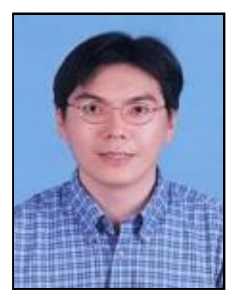

Chung-Wei Feng was born in Taiwan. He obtained $\mathrm{Ph} . \mathrm{D}$ in University of Illinois, USA. He is presently working as an Associate Professor at Department of Civil Engineering in National Cheng Kung University, Taiwan. His research interests are mainly in building information modeling, Artificial Intelligence, and risk management.

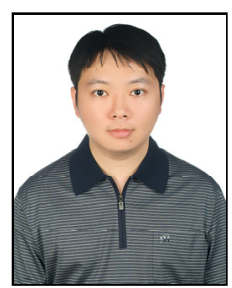

Hsun-Yi Huang was born in Taiwan. He graduated bachelor degree in Feng Chia University and master degree in National Yunlin University of Science and Technology, Taiwan. He is currently a Ph.D candidate from the Department of Civil Engineering in National Cheng Kung University, Taiwan. The focus of his research is in bridge safety issue.

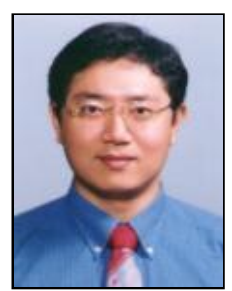

Shen-Haw Ju was born in Taiwan. He obtained $\mathrm{Ph} . \mathrm{D}$ in University of Wisconsin at Madison, USA. $\mathrm{He}$ is presently working as a chairman and a Full Professor of Civil Engineering Department in National Cheng Kung University, Taiwan. His research interests are mainly in structure engineering, finite element analysis, and bridge structure analysis. 